\title{
Del castigo corporal al buen encauzamiento de las conductas en la educación
}

\section{From the body punishment to the good setting of behaviors in education}

Estudio

Juan Illicachi Guzñay

Universidad Nacional de Chimborazo-Ecuador andres1_517@hotmail.com

Recibido: 30 de marzo de 2016 / Aceptado: 09 de enero de 2017

\section{Resumen}

Considerando que el campo educativo es un ámbito privilegiado para estudiar el ejercicio del poder, el artículo analiza la manera cómo opera el poder disciplinar-que se ejerce sobre los cuerpos de los individuos y destinados a vigilarlos, controlarlos y adiestrarlos con el objeto de hacerlos dóciles y útiles- y el biopoder que se ejerce en el cuerpo colectivo de la población y se alimenta de los saberes que se engendran a partir de la propia población-.Y, la manera cómo estas formas de poder en el campo educativo monocultural fue cuestionada y sismada por la educación intercultural bilingüe: primero, porque la institucionalidad intercultural emerge en oposición a la educación hegemónica y como una bandera de lucha política, epistémica del movimiento indígena ecuatoriano. Segundo, porque se constituye en la insurrección y retorno de saber sometido. Aunque la educación intercultural bilingüe, en ocasiones también continúa reproduciendo las mismas formas de constitución de sujetos a través de un determinado número de prácticas de saber-poder.

Descriptores: Ritualidad, disciplina, poder, resistencia, episteme.

\begin{abstract}
Whereas Education is a prime area to study the exercise of power, the article analyzes the way power operates discipline which is exercised over the bodies of individuals and intended to watch them, control them and train them in order to make them docile and useful- and biopower which is exercised in the collective body of the people and feeds on the knowledge that are generated from the population itself. And the way how are you forms of power in the monocultural educational field was challenged and sismada for bilingual intercultural education: first, because the intercultural institutions emerges in opposition to the hegemonic education and as a banner of political struggle, epistemic Ecuadorian indigenous movement. Second, because it is in the insurrection and return knowing subject. Although intercultural bilingual education, sometimes also continues to play the same forms of constitution of subjects through a number of practices of knowledge-power.
\end{abstract}

Keywords: Ritualism, discipline, power, endurance, episteme.

Forma sugerida de citar: Illicachi Guzñay, Juan (2017). Del castigo corporal al buen encauzamiento de las conductas en la educación. Alteridad, 12(1), pp. 104-114. 


\section{Introducción}

El trabajo inicia justificando las razones por las cuales se constituye en una caja de herramientas el horizonte teórico del filósofo francés Michel Foucault en el proyecto de investigación más amplio, aún en curso: "El tránsito de una educación disciplinaria a una educación de control en Riobamba"; del cual es parte, el presente artículo: el primero, es de orden teórico y general: resolviéndose incluir la educación por la importancia que ella tiene para las discusiones en el campo de los estudios Foucaultianos y, especialmente en lo que se refiere a la razón política tematizada por el filósofo. Se "arriesga" a decir que este es un componente imprescindible para la operación de la biopolítica, biopoder y los dispositivos de normalización que se extiende sobre los cuerpos sociales. Un tema que no se desconecta de las categorías de vigilar, castigar y disciplinar. El segundo, es de orden práctico. Los procesos educativos -escolares y no escolares-parecen buenos ejemplos y lugares privilegiados para analizar la manera cómo circula el poder disciplinario, la resistencia, la biopolítica y los dispositivos de normalización (Veiga-Neto, 2013), conociendo que Michel Foucault fue uno de los primeros en detectar del despegue de las sociedades disciplinarias hacia las sociedades de control. Aquí resaltamos las reflexiones de Foucault por medio de los autores de Imperio:

El poder disciplinario mantenía a los individuos en instituciones pero no lograba absorberlos completamente en el ritmo de las prácticas productivas y la socialización productiva; no lograba penetrar eternamente en las conciencias y los cuerpos de los individuos, ni llegaba tratarlos a tratarlos y organizarlos en la totalidad de sus actividades. En la sociedad disciplinaria, la relación entre el poder y el individuo continuaba siendo una relación estática: la invasión disciplinaria del poder correspondía a la resistencia del individuo. En cambio, cuando el poder el poder llega a ser completamente biopolítico, la maquinaria del poder invade el conjunto del cuero social que se desarrolla en su virtualidad. Esta relación es abierta, cualita- tiva y afectiva. La sociedad, absorbida dentro de un poder que se extiende hasta los ganglios de la estructura social y sus procesos de desarrollo, reacciona como un solo cuerpo. El poder se expresa pues como un control que se hunde en las profundidades de las conciencias y los cuerpos de la población y, al mismo tiempo, penetra en la totalidad de las relaciones sociales (Negri y Hardt, 2002, p. 186).

El tercero es de tipo vivencial y personal. El ejercicio docente del investigador en los centros educativos de educación básica, bachillerato y superior bilingüe, y monolingüe, avala hacer el entrecruzamiento de la teoría Foucaultiana con la educación en el espacio de Riobamba. Por último, posiblemente sea el más ambicioso y a largo plazo es la creación de un laboratorio de investigaciones en ciencias sociales que, incorporando el método Foucaultiana en la Universidad Nacional de Chimborazo, atienda el estudio de problemas específicos de la realidad educativa ecuatoriana. De allí la importancia de la formación, investigación y difusión de la obra del filósofo francés, y su uso en el estudio de objetos específicos de la realidad social y educativa.

Por otro lado, Ángel Palerm menciona: "Saludo el futuro en que para los científicos sociales será posible hablar de Marx como los biólogos lo hacen de Darwin y los físicos de Einstein" (2008, p. 46). En esta línea de reflexión, se puede decir que si algún científico social no se sumerge en las profundidades de las líneas maestras del pensamiento foucaultiano: el poder, el saber y el sí, es como si algún sacerdote no leyera la biblia.

Es indudable la gran influencia de Michel Foucault en la filosofía, historia, antropología, teoría social y los estudios culturales contemporáneos, sin embargo, en las academias periféricas parece no nacer ni Foucault ni su pensamiento, constituyéndose en una teoría privilegiada solamente de los centros universitarios ubicados en las metrópolis. La ausencia de las obras foucaultianas en las estanterías de las librerías y bibliotecas en los espacios periféricos es visible. Esta crisis en parte puede ser por lo que argumenta Aída Hernández: 
Desafortunadamente la información y las personas no fluyen tan fácilmente de sur a sur, como lo hacen el capital y la fuerza laboral (cuando se le requiere) de norte a sur y de sur a norte, respectivamente. El intercambio político e intelectual entre América Latina, África y Asia se ha visto limitado por barreras lingüísticas y por la precariedad de nuestras industrias editoriales e instituciones científicas y educativas (2014, p. 195).

La estrategia de adoptar y emplear la teoría del filósofo Michel Foucault para estudiar el campo educativo en el contexto de Riobamba no implica ubicar los debates como una simple recepción, como si fuéramos la sucursal latinoamericana o riobambeña de una compañía transnacional llamada "trilogía conceptual: poder, saber y subjetividad", sino mostrar que la especificidad del debate latinoamericano sólo puede apreciar $a$ contraluz de lo que en otros lugares se ha venido discutiendo bajo esta rúbrica (Castro-Gómez, 2005). Es más, Foucault no solo forma parte de los llamados clásicos, sino que sigue siendo parte de la inquietud del pensamiento contemporáneo que no se ubica más en la verdad, sino en la coherencia de los discursos, en las redes de redes que se comunican (Lechuga, 2007). De ninguna manera hay la pretensión de invisibilizar los puntos ciegos o los límites ${ }^{1}$ de la teoría Foucaultiana.

Con estos antecedentes, el texto analiza la manera cómo los castigos en la educación eran ritualizados públicamente. El cuerpo es el lugar donde se ejerce el poder educativo, siendo el cuerpo y la mente escolar el objeto de poder o de la colonialidad: colonialidad del saber, colonialidad del ser, fabricando a su interés; es decir,

\footnotetext{
En una de las críticas, que puede ser aplicable también en la educación, Silvia Federici, en su libro: Calibán y la bruja. Mujeres, cuerpo y acumulación originaria sostiene: "Por su parte, las feministas han acusado al discurso de Foucault sobre la sexualidad de omitir la diferencia sexual, al mismo tiempo que se apropiaba de muchos saberes desarrollados por el Movimiento Feminista. Esta crítica es bastante acertada... Más aún, Foucault está tan intrigado por el carácter productivo de las técnicas del poder de las que el cuerpo ha sido investido que su análisis deja prácticamente fuera cualquier crítica de las relaciones de poder (2016, p. 29).
}

individuos obedientes, sumiso y dóciles. La ritualización del castigo al cuerpo del niño y del joven indígena en los espacios escolares era más radical que en la ciudad. Frente a esta educación punitiva, coercitiva surge la educación intercultural bilingüe como una alternativa y en oposición a la educación monocultural. Son éstos los temas que trata el texto en las siguientes secciones a la luz de la teoría foucaultiana y del trabajo de campo etnográfico. Se esgrimió las entrevistas, las historias de vida, la observación participante. Predominó un enfoque antropológico colaborativo y militante, una investigación emic y no etic, rompiendo con las perspectivas tradicionales de investigación que concebía a los interlocutores como meros "objetos de estudio".

\section{El castigo al cuerpo: ritualidades}

En la educación ecuatoriana, la frase "la letra con sangre entra" operaba con naturalidad y normalidad en las aulas educativas, y con más radicalidad en los espacios rurales e indígenas. De cierta manera la escuela se constituía en una especie de panoptismo ${ }^{2}$ no porque sea un centro carcelario ${ }^{3}$ sino porque se constituía en la casa de inspección, de control del poder. La escuela es una construcción arquitectónica desde donde se dirige y se vigila a las multitudes, en los patios, en los pasillos, en las gradas, en las aulas. Un solo individuo puede controlar y disciplinar a toda una multitud, por ejemplo, el inspector general logra controlar las conductas de un colectivo de mil estudiantes en los patios de la institución. De la misma manera, un docente puede vigilar y castigar, casi, en forma ritualizada a sus discípulos. En este sentido el sujeto-alumno no es abstracto, incorpóreo,

2 La categoría panóptica para Michel Foucault es “una forma en que el poder se materializa en dispositivos arquitectónicos, pero también en un régimen de mirada. Un proyecto de verlo y vigilarlo todo desde un solo punto" (Parrini, 2007, p. 16).

3 Aunque para Miguel Morey: “No sólo los prisioneros son tratados como niños, sino que los niños son tratados como prisioneros. Los niños sufren una infantilización que no es la suya. En este sentido es cierto que las escuelas son un poco prisiones, y las fábricas mucho más" (2008, p. 28). 
vacío, sino que el sujeto se define en el cuerpo a partir de los regímenes del saber y del poder (Lechuga, 2007). El cuerpo es el lugar donde se ejerce el poder educativo. Dicho de otra manera, el cuerpo escolar fue blanco y objeto de poder y saber. El cuerpo escolar siendo un objeto de poder, al entrar en el dominio del poder es fabricado a su interés; o sea, individuos obedientes.

El castigo físico a los y las estudiantes se expresaba de múltiples maneras: con empujones contra el pizarrón; los reglazos en cualquier parte del cuerpo, preferentemente, en las manos o en la cabeza; los pellizcos; los golpes, las sacudidas; las tiradas de las orejas. Estos castigos cumplían el rol de corregir, guiar, mejorar las fallas cometidas (Herrera, 2013). La intención es dominarlos, disminuirlos, sumirlos, hasta el punto de obtener la entrega de sus voluntades y sus espíritus.

Las razones por las cuales violentaban los cuerpos escolares no faltaban, sin embargo citamos algunas con fines ilustrativos: por las malas letras; por ingresar con la comida al salón de clase; por levantarse sin autorización del docente; por ensuciar los cuadernos, por doblar los filos de los libros, etc., sobraban los motivos para los castigos. Los cuerpos se sometían a la docilidad, la obediencia, disciplina y corrección con el fin de hacerlos trabajar y convertirlos en productivos, en fuerza de trabajo físico e intelectual (Lechuga, 2007).

La violencia al cuerpo escolar no se avergonzaba, se expresaba de manera directa e incluso exhibiéndose públicamente, mientras más se presentaba en público más efectivo era el castigo, por ejemplo, uno de los maestros entrevistados revela que el castigo denominado plantón, consistía en hacerle "parar" al estudiante de espaldas en un rincón del aula por mucho tiempo sin que el afectado volteara a mirar a quien ejerce el poder ni a sus espectadores, en este caso sus compañeros del aula. $\mathrm{El}$ individuo individualizado se ubica en un espacio reducido, recortado, vigilado en todos sus puntos, en el que los menores movimientos se hallan controlados, en el que todos los acontecimientos se encuentran registrados (Foucault, 2009). De cierta manera, aquí funciona la fórmula "el observador puede ver al observado y no a la inversa". Al menos en este tipo de castigo el estudiante cercado no puede ver, pero sí, quien ejerce el poder.

Para algunos docentes no era correcto castigar pero admiten que era la mejor forma de educar y hasta expresan su extrañez:

Porque la educación de antes era mejor que la de ahora. Hoy no se puede tocarles, tienen protección del Ministerio de Educación, del Código de la Niñez y de la Adolescencia. No hay miedo a nada, por eso son muy irresponsables (Anónimo, 15 de junio de 2015).

De acuerdo a este testimonio el castigo físico fabricaría el tipo de sujeto responsable, cumplidor y tímido. Esta extrañeza al "pasado", a la forma de educar con castigo también es añorada por algunos estudiantes universitarios, futuros maestros, aunque sugieren "un castigo suave" para formar ciudadanos responsables, respetuosos, a la vez que insinúan aplicar "mano dura" desde la docencia, admitiendo que él es un buen estudiante porque tuvo profesores con "mano dura". Esta narrativa ambigua y contradictoria no solamente circula en los estudiantes y profesores, también son reproducidas por los padres de familia; por un lado cuestionan el castigo al cuerpo de sus hijos, por otro lado ven la necesidad de su presencia y aplicación, incluso en ocasiones sugieren medidas enérgicas para que su hijo sea disciplinado. En este sentido, las "estrategias", "programas" y "tecnologías" de poder se justifican como necesidad y poder moral (Morey, 2008; Gledhill, 2000). “Tengo razón en castigar, puesto que tú sabes que está mal robar, matar, no hacer los deberes, atrasarse,..." (Morey, 2008, p. 28).

Algunos instrumentos empleados para el castigo al cuerpo de los escolares variaban en los escenarios urbano/rural, campo/ciudad. El cuerpo indígena no era el mismo cuerpo del mestizo o del blanco, era el cuerpo del no humano, era el cuerpo del no ser; por lo tanto, el cuerpo animalizado debía ser tratado sin consideración alguna, con acciones represivas. La ritualización del castigo al cuerpo del niño y del joven indígena en el 
campo escolar era más radical que en la ciudad; por ejemplo, se le aplicaba la "fila india", que consistía en formar dos columnas de estudiantes para que por medio de ella pasara el cuerpo indisciplinado recibiendo patadas, puñetes, murmullos, silbidos, gritos. El ritual se solemnizaba aún más, cuando alguien de la fila "por consideración o amistad" no se insertaba en ese juego de poder, corría con la misma suerte de ser castigado.

En este sentido, la tecnología disciplinaria fija, inmoviliza o regula los movimientos; resuelve las confusiones, las aglomeraciones compactas sobre las circulaciones inciertas, las distribuciones calculadas (Foucault, 2009), pero en definitiva quien domina, contrala y direcciona los comportamientos y las fuerzas de los estudiantes son los profesores o cualquier autoridad educativa, sin embargo, no se puede negar de los momentos y formas de resistencias 4 imprevistas e imprevisible de los estudiantes o habrá que explorar los nuevos tipos de luchas de los estudiantes, por ejemplo, las luchas no centralizadas, las luchas transversales (Negri, 2004; Delueze, 2014[1986]), tema que será analizado a profundidad en los posteriores artículos.

Otro instrumento de castigo empleado en el ámbito escolar es la aplicación del ramo de ortiga ${ }^{5}$ negra en el cuello del "afectado", o el hecho de azotar en las manos, produciendo inflamación e irritación en la piel con el picor intenso. El sufrimiento del castigo se debe a que la ortiga, al tener pelos y espinas, liberan una sustancia ácida que produce escozor en la piel.

El instrumento de castigo en las escuelas rurales eran las pepas de eucalipto, los mismos estudiantes solían recoger en un bosque cercano a la institución, sobre esas pepas se ponían de

4 Referente a la resistencia, Gilles Deleuze, citado en Miguel Morey sostiene: "Si los niños llegasen a hacer oír sus protestas en una escuela de párvulos, o incluso simplemente sus preguntas, eso bastaría para provocar una explosión en el conjunto del sistema de enseñanza" (2008, p. 27).

5 La ortiga tiene el tallo de sección de forma de cuadrado, hojas con forma de ovalo, con el borde aserrado. La característica más conocida de esta planta es presencia de pelos urticantes cuyo líquido cáustico produce una irritación con picor intenso en la piel cuando se le toca o roza. rodillas los estudiantes indisciplinados, luego de varios minutos se levantaban con heridas, gotas de sangre rodaban por las rodillas al ritmo de las gotas de lágrimas que rodaban por las mejillas. Dentro o sobre el escritorio del profesor se exhibía un látigo ${ }^{6}$ de cuero de vaca, también denominado "veta" o "azote". Los latigazos provocaban dolores insoportables y sangrados. Tanto los "hortigazos" como los "latigazos", frecuentemente, solían aplicar en los glúteos haciéndoles desvestir sea a mujer o varón, sin ningún pudor. El uso de los latigazos era común y natural en las escuelas, incluso los mismos padres de familia llevaban y les entregaban al profesor, los mismos representantes solicitaban a los profesores que castiguen, como nos relata en una de las entrevistas. Era una de las maneras de normalizar el uso del látigo en los cuerpos de los indisciplinados. Mientras más "bravo", violento era el profesor era considerado como el mejor profesor. La indisciplina de los alumnos era atribuida a la mansedumbre del docente. El látigo era un instrumento que producía fuertes dolores, sin embargo era normal ver a los estudiantes con huellas de los latigazos, era natural ver al docente en los patios, aulas con látigo en mano. El uso de este objeto era sinónimo de corrección y disciplinamiento, hoy es un objeto sinónimo de maltrato y agresión. En ausencia del látigo reemplazaba las denominadas "varas" o ramas de las plantas o de los árboles, señala uno de los entrevistados.

A este tipo de educación punitiva y coercitiva acompañaba los discursos humillantes, discriminantes, machistas, racistas. Por ejemplo, era común escuchar: "Tu no sirves sino para pastorear chivos; en vez de gastar el dinero produce cuidando chanchos; lárgate al páramo y no vuelvas nunca a mi clase". En este sentido la edu-

6 El látigo es un objeto multifuncional esgrimido no solamente por el profesor sino también por los padres de familia para corregir el comportamiento de sus hijos. De acuerdo a las narrativas señalan que el mismo objeto servía para castigar a los indígenas mayores de parte de los hacendados, pero además el indígena besaba el látigo luego de recibir el castigo como signo de humildad y agradecimiento. Este mismo objeto fue empleado para acarrear a los animales, para educar los estudiantes, para disciplinar los indígenas. 
cación se constituye en un instrumento de poder que se impone mediante técnicas, muchas veces sofisticadas e invisibles, de estandarización, de "normalización", que hacen que la escuela, al igual que el cuartel o la fábrica, se parezcan a la cárcel moderna (Foucault, 2009 [1976]). Aunque similar discurso fue expresado por el sociólogo francés Emile Durkheim (1976). Desde su abordaje, la educación moral que se desarrolla en la escuela es clave en la sociedad moderna para someter a los jóvenes a un conjunto de reglas que, a la vez que se imponen como mandatos, generan la regularidad de hábitos necesaria en la sociedad industrial.

\section{Del castigo al cuerpo al control de las almas}

En la actualidad -en el área donde se ejecuta la presente investigación- una de las maneras de controlar, vigilar y castigar no es al cuerpo, sino al alma. La exhibición, la ritualidad del castigo físico, la educación punitiva se diluye, opera de modo más transformada. Porque el castigo físico se considera como una práctica inconveniente, peligrosa e inadecuada para educar a los niños y jóvenes (Herrera, 2013). Los castigos dolorosos, el castigo físico sobre el cuerpo de los niños en la escuela, por considerarlo nocivo y vejatorio han sido cuestionados, denunciados y suprimidos. Se afirma que la fuerza física no asegura ni la autoridad por parte del maestro, ni la obediencia en el discípulo (Herrera, 2013) no obstante, la intromisión de la política y del poder sobre el $b i o^{7}$ de los

7 El biopoder interviene y extiende la vida. La biopolítica dice interesarse por educar y formar físicamente para la vida (Tejeda, 2012, p. 20). A partir de la década de los 70 , con los aportes de Michel Foucault, se introduce en el pensar filosófico las categorías de biopoder y biopolítica para aludir al cambio de paradigma que inaugura el pasaje de las sociedades disciplinarias modernas a las sociedades de control o posmoderna. En realidad, el término biopoder es más amplio que biopolítica, ya que el primero implica el poder que se ejerce sobre la vida de las personas desde cualquier contexto (hospitalario, escolar, empresarial) mientras el segundo refiere específicamente al manejo de la vida de las personas desde la acción del Estado (Lesteime, 2011). individuos y multitudes escolares continúa siendo parte de la educación.

Una de las razones para que los castigos corporales cedan su puesto a los medios espirituales y almas es por los cuestionamientos de la educación intercultural bilingüe (EIB), no por eso se puede decir que las técnicas de control y de la vigilancia a los individuos se han erradicado. En la EIB, también el poder se inmiscuye en la intimidad y penetra cuerpos y mentalidades del mismo modo que en la educación hegemónica y monolingüe. En la EIB, el poder cuida y conserva el cuerpo, ya no reduce o maltrata el cuerpo escolar y colegial, de ahí la relevancia que adquiere el cuerpo escolar indígena como portador de la identidad cultural: vestido, cabello largo. En este sentido, ahora son exaltados los cuerpos indígenas esculpidos y violentados históricamente, ahora son valorados y humanizados los cuerpos indígenas animalizados (Tejeda, 2012).

Evidentemente, en este campo, el funcionamiento del poder positivo no es, en modo alguno, un poder represivo, sino productivo, un poder inventivo y no conservador. El descubrimiento de Foucault del poder positivo radica en que su funcionamiento no se reduce a decir "no", ni a prohibir, impedir, obstaculizar; si el poder no tuviera más funciones que las de excluir y reprimir, "si no se ejerciera más que de una manera negativa, sería muy frágil". Si es fuerte, es debido a que produce efectos positivos a nivel del deseo y también a nivel del saber (Lechuga, 2007, p. 117).

Las relaciones de poder no deben limitarse a la posibilidad de la violencia, pues son un conjunto de mecanismos y tecnologías muy complejas cuya esencia no es prohibir, sino vigilar, controlar conductas, ocuparse del desarrollo de la gente en instituciones como las escolares, y actuar sobre sus gestos, sus maneras de actuar, sus aptitudes (Lechuga, 2007, p. 120).

No obstante del pasaje de una educación punitiva a una educación positiva, del tránsito de una educación prohibitiva a una educación de 
permisiva ${ }^{8}$, ambas formas de educación continua siendo -en la práctica- monolingüe, monocultural, hegemónica. En este sentido:

El sistema educativo recrea y reproduce las jerarquías raciales de la sociedad ecuatoriana. Es más, la mayoría de los educadores reproducen las jerarquías raciales en sus salones de clase. Por lo tanto, el paso por la escuela, el colegio y la universidad son, por lo general, experiencias traumáticas llenas de vejámenes y obstáculos (De la Torre, 1996, p. 34).

En oposición a este tipo de educación y como alternativa emerge la educación intercultural bilingüe ${ }^{9}$ como un proyecto político, epistémico de los pueblos indígenas, que atenúa a la forma de educación prohibitiva/ productiva.

\section{EIB como proyecto político y epistémico}

En este apartado empiezo formulando algunas preguntas de corte epistémico. ¿Qué implica considerar a la EIB como un proyecto epistémico? ¿La irrupción de la EIB al sistema educativo nacional colonial ha contribuido a la toma conciencia del proceso propio de conocimiento y del

8 "Se me ocurrió cantar, inconscientemente, el profesor sin dudar y de buena manera me dijo que cantara para todos. Pero me dio mucha vergüenza". Pues, aquí funciona el poder facultativo, permisivo.

9 La Dirección Nacional de Educación Intercultural Bilingüe, DINEIB, fue creada mediante Decreto Ejecutivo No. 203 del 9 de noviembre de 1988, publicado en el Registro Oficial No. 66 de 15 del mismo mes y año, para atender las necesidades educativas de la población indígena del país. Entre sus funciones, se responsabiliza del desarrollo del currículo apropiado para cada uno de los sistemas y modalidades de educación intercultural bilingüe, así como de la promoción y fortalecimiento de las lenguas indígenas. Mediante Ley No. 150 de 15 de abril de 1992, publicada en el Registro Oficial No. 918 de 20 de abril del mismo año, se eleva a la DINEIB al nivel de un organismo técnico, administrativo y financiero descentralizado; y para su funcionamiento cuenta con su propia estructura orgánica funcional. De la misma manera, en 1992, se oficializa el Sistema de Modelo de Educación Intercultural Bilingüe con fundamentos filosóficos, jurídicos, pedagógicos y psicológicos. Más adelante, en el año 2003, fue rediseñado sobre la base de las diferentes experiencias de EIB en el país (MOSEIB, 1992; García, 2007; Zavala, 2007; Martínez, 2009). saber indígena? La institucionalización de la EIB vehiculiza -en términos foucaultianos- la lucha por la insurrección de los saberes sometidos:

Y por saber sometido entiendo dos cosas. Por una parte, quiero designar, en suma, contenidos históricos que fueron sepultados, enmascarados en coherencias funcionales o sistematizaciones formales...En segundo lugar, por saber sometido creo que hay que entender otra cosa y, en cierto sentido, una cosa muy distinta. Con esa expresión me refiero, igualmente, a toda una serie de saberes que estaban descalificados como saberes no conceptuales, como saberes insuficientemente elaborados: saberes ingenuos, saberes jerárquicamente inferiores, saberes por debajo del nivel del conocimiento o de la cientificidad exigidos (Foucault, 2006 [1976], p. 21).

La recuperación de los saberes sometidos o los intentos por la recuperación por medio de la EIB no se dan en un campo pacífico, sino en un campo de lucha permanente que desafía a un orden institucional históricamente jerárquico, que busca enfrentar los legados coloniales, incluyendo las geopolíticas del conocimiento. Aquí es interesante importante señalar la nueva, o mejor dicho, la renovada atención puesta por grupos indígenas y afros al pensamiento como campo de lucha, intervención y creación, haciendo así evidente un proyecto de la EIB que no es sólo político, sino también epistémico (Walsh, 2007) en el sentido de imaginar también no ya "nuevos paradigmas" inscritos en el proyecto de la modernidad (tanto colonizadores como liberadores), del cual el proyecto del neoliberalismo es parte y consecuencia, sino de "paradigmas otros" (Mignolo, 2000), que afectan y deslegitiman el currículo nacional hegemónico, con la insurgencia de un saber sometido, condensado en el Modelo del Sistema de Educación Intercultural Bilingüe (MOSEIB). La insurgencia de un saber sometido, según Luis Macas (2005) va en contradicción directa con el pensamiento occidental. Para este activista e intelectual indígena existen dos luchas paralelas y de carácter fundamental. La primera hace referencia 
a los desafíos que tienen las comunidades y pueblos indígenas frente a los embates de la globalización. La segunda se refiere a la disputa que existe en el terreno del conocimiento, en la formación de los saberes. En este juego de lucha, la emergencia de la EIB, por lo menos en su discurso, intenta descolonizar la educación oficial hegemónica, punitiva, excluyente; pero no desde fuera de la estructura sino desde dentro; por tanto, la lucha es "legal" y "admitida". El movimiento indígena ecuatoriano no pretende ni nunca ha pretendido actuar y definirse fuera del Estado:

El poder es del pueblo, no del gobernante. Queremos que el gobierno de Rafael Correa termine su mandato pero debe escuchar el clamor popular. No queremos que se caiga el gobierno, queremos que se caiga el sistema corrupto que le rodea... (Discurso del nuevo presidente $10^{12}$ de Ecuarunari, 21 de diciembre del 2009).

De cierta manera, la aparición de la EIB reconocida por el Estado ecuatoriano, significó una justicia social que implica justicia cognitiva, ontológica e histórica. Es decir, evitar el olvido histórico (de dónde venimos), el olvido epistemológico (qué sabemos) y el olvido ontológico (quiénes somos) (De Sousa Santos, 2010).

Varios indígenas intelectuales se casaron con las mestizas a fin de olvidar su condición de indígena, querían escapar de su lengua,...La institucionalización de la Educación Bilingüe detiene a esa escapatoria. Indígenas que querían desindigenizarse ven en la Educación Bilingüe un espacio, su espacio de reflexión y de concientización... (Carlos Moreno, 9 de enero de 2014).

Este testimonio evidencia la negación de su propia existencia: la colonialidad del ser. La colonialidad del ser se refiere a la no-existencia y la deshumanización, una negación del status del

10 En el III Congreso de la Ecuarunari (movimiento indígena de alcance regionall) fue electo unánimemente, representante de la Confederación del Movimiento Indígena de Chimborazo (CO-MICH), Delfín Tenesaca. ser humano que se inició dentro de los sistemas de complicidad del colonialismo y esclavitud (Walsh, 2007).

El matrimonio "ansiado" de un indígena con una mestiza -luego de su movilidad social a través de la educación- ve, al parecer, la necesidad de blanquearse, transformándose y modificándose, dejando de ser para ser un no ser. Pero también, la subjetividad sería siempre una manera de ser y, al mismo tiempo, de no ser. Similar a este testimonio parece muy frecuente, no descubrir qué somos, sino rechazar lo que somos. Imaginado y creando lo que podríamos ser, borrando su ser o nuestro ser. En definitiva, traza la línea de fuga para escapar de los mecanismos y estructuras modernas de saber-poder, por medio de la desindigenización.

A fin de bloquear la línea de fuga, la EIB crea programas de alfabetización, instituciones educativas de todos los niveles, (centros educativos comunitarios, colegios, institutos, universidades) y, además, estas entidades educativas se articulan como un andamiaje en la formación de conciencia crítica, constituyéndose parte del proceso del despertar indígena. A pesar de estos objetivos, la EIB, desde sus inicios, operaba con una serie de dificultades como la escasez de maestros entrenados en las áreas de kichwa y cultura; paradójicamente algunas de las posiciones creadas por el Ministerio de Educación para profesores bilingües han sido ocupadas por no-bilingües debido a la falta de profesionales con formación en las materias que debían enseñarse en el sistema intercultural (Montaluisa, 1990 citado en Martínez Novo, 2009).

No estábamos preparados para el nacimiento de la EIB. La EIB surge en el momento menos esperado y menos preparado. La reacción de los padres de familia fue adversa, también fue así de las comunidades indígenas. De las reuniones cerradas dentro del Ministerio y de la CONAIE surge la EIB, sin previa planificación. No estábamos preparados para administrar muchos centros educativos, sino pocos (Emilio Ajitimbay, 29 de enero del 2014). 
Este testimonio concuerda con la siguiente hipótesis:

[...] la preservación de las lenguas y culturas indígenas ha sido más un objetivo de ciertos agentes externos como los etno-lingüistas, la Iglesia progresista y la izquierda, y de algunos líderes indígenas, que un deseo de los indígenas de base (Martínez, 2009, p. 192).

La pregunta que surge es: ¿Algunas experiencias educativas, como Escuelas Radiofónicas Populares del Ecuador-ERPE, no sirvieron para la concientización? Más allá de la respuesta afirmativa o negativa, el intento de reaparición de esos saberes de abajo, de esos saberes no calificados y hasta descalificados, de esos saberes locales, de esos saberes particulares -Foucault (2006 [1976]) diría, saber de la gente-, yo diría saberes de los pueblos indígenas, encuentran limitaciones, tensiones y ambigüedades en los protagonistas de casa adentro y casa afuera $11^{13}$, que no permiten enfrentar la colonialidad del saber y la geopolítica dominante del conocimiento $12^{14}$. Además, las cuestiones del apartado anterior -del ser dejando de ser, ¿qué somos? Y en términos Foucaultianos diríamos: ¿Qué es el sujeto?- no es solamente un problema ontológico; también contienen dos dimensiones: una dimensión ética y política, $y$ otra epistemológica. La primera se referiría no sólo a cuál es el tipo de relación establecida entre quién es considerado ser y quién no, sino también cuáles son los propósitos de su negación y afirmación de su condición de ser. Por otra parte, la dimensión epistémica indica las condiciones de posibilidad de conocimiento en sí. Esto se evidencia, por ejemplo, en la presentación de iconografías de los pueblos, nacionalidades indígenas y afroecuatorianos en los textos escolares llamados

11 La casa adentro indica los procesos internos de las organizaciones, pero más que todo de las comunidades, para construir y fortalecer un pensamiento y un conocimiento propios.

12 Para Catherine Walsh, la manera de enfrentar la colonialidad del saber es reconstruyendo y fortaleciendo pensamientos y conocimientos propios, no como un saber folclórico local, sino como epistemología, sistemas de conocimiento (2007). kukayos pedagógicos. Este conocimiento (saber) de sí (ser) pone en duda a la legitimidad y hegemonía de las representaciones y conocimientos y, en términos de estos últimos, los contenidos indígenas son puestos en las aulas escolares de todos los niveles interculturales bilingües como la historia de los líderes indígenas $13^{15}$, de las organizaciones indígenas, las tradiciones y costumbres de los pueblos o nacionalidades y sus cosmovisiones. Estos textos, nunca entraron por lo menos a los archivos de los centros escolares monolingües de cantón Riobamba. En este sentido, la EIB socava al conocimiento "universal" y colonial, constituyéndose en un aporte a la insurgencia de los saberes sometidos.

Por otro lado, la EIB no está distante de algunas dificultades como los kukayos pedagógicos abandonados en varios centros educativos con poco interés hacia los contenidos indígenas; esto se debe a que algunos maestros hispanos e indígenas no estaban preparados para recibir y utilizar textos autoimaginados por los propios actores $\mathrm{y}$, paralelamente a la producción de los kukayos pedagógicos, no se elaboraron materiales didácticos para profesores y estudiantes en las diversas lenguas indígenas a nivel institucional, con excepción de algunos esfuerzos desde los niveles regionales o provinciales. Las imágenes fabricadas y su circulación en los textos escolares, están íntimamente ligadas a la cosmovisión de cada particularidad indígena. Dichos discursos representacionales, tanto los narrados como los visuales, informarían sobre los "indios imaginados", los que en distintos periodos históricos se han convertido en un capital cultural que ha servido a los intereses de los distintos imagineros (Muratorio, 1994, p. 10).

Estas ambigüedades y contradicciones en el campo epistémico y político no solo existen entre la EIB y el Estado, sino también dentro de los propios agentes interculturales bilingües. Por un lado, se le da

13 En los textos Kukayos pedagógicos elaborados por la Dirección Regional Sierra, aparecen la vida, lucha y pensamiento de indígenas como Alejo Sáes, Fernando Daquilema y Dolores Cacuango, también las historias de la CONAIE, ECUARUARI y demás organizaciones indígenas. 
poca importancia al conocimiento de los mayores y a las formas no occidentales de inscribir y transmitir conocimiento, como menciona Carmen Martínez Novo (2009); en el campo lingüístico acontece un hecho similar: los maestros pasan la mayoría de su tiempo enseñando alfabetización en español, los padres demandan que se les eduque a sus hijos en español y que se les enseñe a leer y a escribir en este idioma (2009). Por otro lado, el discurso oficial -sometido dentro de un campo de lucha contra la estructura y contra sus propios agentes- continúa exigiendo la aplicación de los principio lingüísticos: "la lengua nativa constituye la lengua principal de educación y el español tiene el rol de segunda lengua y lengua de relación intercultural" (MOSEIB, 1992, p. 13); y, en término epistemológicos, el Modelo de la EIB menciona: "desarrollar un programa que rescate y actualice la etnociencia de acuerdo con la teoría integrada de la ciencia y la cosmovisión que caracteriza a los pueblos indígenas" (1992, p. 12). Parece no solo haber distancia entre los discursos y las prácticas educativas sino, también, en un campo de lucha permanente, en una doble vía: contra el Estado y entre y desde sus propios agentes.

\section{Conclusiones}

En el campo educativo, al decir de Julia Varela (1993), Michel Foucault, como es bien sabido, nunca dedicó a la educación un trabajo sistemático y acabado. Sin embargo, muestra las relaciones y juegos de poder en las relaciones pedagógicas, por ejemplo en la transmisión de saberes, cuando se acepta que alguien sabe más que otro (Lechuga, 2007). Por eso, el pensamiento de Foucault cobra vigencia en el campo educativo en tanto que en Vigilar y castigar no analiza únicamente las cárceles sino también el hospital, la escuela, el orfelinato y la fábrica.

Así como la educación es un ámbito privilegiado para el ejercicio del poder, pues también es uno de los escenarios de resistencias e insurrecciones políticas, epistémicas, aunque John Gledhill (2000) afirme que "el poder provoca inevitablemente "resistencias" tiene poca base real. Sin embargo, la palabra clave para entender los juegos de poder y evitar caer en la dominación es la resistencia; pues, donde hay poder hay resistencia. Hay resistencia cuando alguien dice "no", cuando se opone a una situación determinada con la intención de modificarla o bien evitarla. Su modelo "capilar" del poder privilegia la micropolítica de la resistencia o la infraeducativa.

El castigo físico a los y las estudiantes se expresaba de múltiples maneras: con empujones contra el pizarrón; los reglazos en cualquier parte del cuerpo, preferentemente, en las manos o en la cabeza; los pellizcos; los golpes, las sacudidas; las tiradas de las orejas. Estos castigos cumplían el rol de corregir, guiar, mejorar las fallas cometidas. Los cuerpos se sometían a la docilidad, la obediencia, disciplina y corrección con el fin de hacerlos trabajar y convertirlos en productivos, en fuerza de trabajo físico e intelectual. La violencia al cuerpo escolar no se avergonzaba, se expresaba exhibiéndose públicamente. Mientras más se presentaba en público más efectivo era el castigo.

Frente a una educación punitiva, centralizada en el castigo ritualizado al cuerpo, bancaria; frente al sistema educativo que recrea y reproduce las jerarquías raciales de la sociedad ecuatoriana; frente a cierto educadores que reproducen las jerarquías raciales en sus salones de clase; frente a la producción experiencias traumáticas llenas de vejámenes y obstáculos en el paso por la escuela, el colegio y la universidad (De la Torre, 1996), emerge la educación intercultural bilingüe como una alternativa y un proyecto político, epistémico de los pueblos indígenas, que atenúa a la forma de educación prohibitiva/ productiva; aunque en ocasiones reproduce los mismos "vicios" que el sistema educativo tradicional. De cierta manera, expresa el tránsito de una educación disciplinaria a una educación de control.

\section{Referencias bibliográficas}
Castro-Gómez, S. (2005). La poscolonialidad explica- da a los niños. Bogotá: Universidad del Cauca y Universidad Javeriana.


De la Torre, C. (1996). El racismo en el Ecuador. Quito: Abya-Yala.

Deleuze, G. (2014) [1986]. El poder. Curso sobre Foucault. Tomo II. Buenos Aires: Cactus.

De Sousa Santos, B. (2010). Enriquecer la democracia construyendo la plurinacionalidad. Quito: Fundación Rosa Luxemburgo.

Dirección de Educación Intercultural Bilingüe (1992). Sistema de Educación Intercultural Bilingüe. Quito: EIB.

Durkheim, E. (1976). Educación y sociología. Bogotá: Editorial Linotipo.

García, F. (2007). Los pueblos indígenas del Ecuador: derechos y bienestar. Informa alternativo sobre el cumplimiento del Convenio 169 de la OIT. Quito: FLACSO.

Federici, S. (2016). Calibán y la bruja. Mujeres, cuerpo y acumulación originaria. Quito: Abya-Yala.

Foucault, M. (2006) [1976]. Defender la sociedad. México: Fondo de Cultura Económica. (2009) [1976]. Vigilar y castigar. México: Siglo Veintiuno.

Hernández, A. (2014). Diálogos Sur-Sur: Una lectura latinoamericana de los feminismos poscoloniales. En: K. Bidaseca y J. Obarrio (Comps.), Legados, genealogías y memorias poscoloniales en América Latina: Escrituras fronterizas desde el Sur (pp. 162-195). Buenos Aires: Godot.

Herrera, C. (2013). Castigos corporales y escuela en la Colombia de los siglos XIX y XX. Revista Iberoamericana de Educación, 62, 69-87.

Gledhill, J. (2000). El poder y sus disfraces. Barcelona: Ediciones Ballaterra.

Macas, L. (2005). La necesidad política de una reconstrucción epistémica de los saberes ancestrales. Buenos Aires: Clacso.

Lechuga, G. (2007). Foucault. México: Universidad Autónoma Metropolitana.
Lesteime, D. (2011). Ciencia y biopoder: del discurso científico a la instrumentalización biopolítica del saber. Revistas Colombiana de Filosofía de la Ciencia, 22, 47-53.

Martínez, C. (2009). La crisis del proyecto cultural del movimiento indígena. En: C. Martínez (Comp.), Repensando los movimientos indígenas (pp. 173-196). Quito: FLACSO-Ecuador.

Mignolo, W. (2000). Historias locales/diseños globales. Madrid: Akal.

Morey, M. (2008). Michel Foucault, un diálogo sobre el poder y otras conversaciones. Barcelona: Alianza Editorial.

Muratorio, B. (1994). Introducción: discursos y silencios sobre el indio en la conciencia nacional. En: B. Muratorio (Comp.), Imágenes e imagineros (pp. 9-24). Quito: FLACSO-Ecuador.

Negri, A. (2004). Multitud. Guerra y democracia en la era del imperio. Barcelona: Limppergraf.

Negri, A. y Hardt, M. (2002). Imperio. Barcelona: Limppergraf.

Palerm, Á. (2008). Antropología y marxismo. México: CIESAS.

Parrini, R. (2007). Panópticos y laberintos. Subjetivación, deseo y corporalidad en una cárcel de hombres. México: El Colegio de México.

Tejeda, J. (2012). Biopoder en los cuerpos. Revista Memoria Académica, 1, 13-25.

Walsh, C. (2007). Interculturalidad colonialidad y educación. Revista Educción y Pedagogía, 48, 25-35.

Varela, J. (1993). Prólogo a la edición española. En: Foucault y educación. Disciplinas y saber, 5-10.

Veiga-Neto, A. (2013). Biopolítica, normalización y educación. Cuadernos de Pensamiento Biopolítico Latinoamericano, 1, 10-20. 